Case 2

A 26 year old waitress with chronic alcohol abuse was admitted because of increasing, predominantly left sided abdominal pain for three weeks, formation of ascites, and yellow vaginal discharge. Laboratory findings were normal except for a sedimentation rate of $44 \mathrm{~mm}$ in the first hour and platele count of $511 \times 10^{9} / 1$. Laparoscopy showed severe diffuse fibrinous peritonitis, most pronounced in the right upper quadrant, and a moderate amount of ascites. $C$ trachomatis was cultured from the ascites and vaginal discharge. The patient was treated successfully with doxycycline $200 \mathrm{mg}$ daily for 10 days.

\section{Comment}

Shabot and colleagues found $C$ trachomatis in ascitic fluid of patients with chronic liver disease but were unable to say whether the organism was pathogenic in those cases. ${ }^{3}$ Diffuse peritonitis and ascites formation in our patients without chronic liver disease were definitely due to an infectious agent, as shown by the rapid response to antibiotic treatment. Preceding genital infection and manipulation of the uterus are classic features of the Fitz-Hugh-Curtis syndrome. $C$ trachomatis was the most likely aetiological agent in both patients.
In case 2 the organism was cultured from the cervical secretion and ascitic fluid and in case 1 the patient showed a fourfold decline of immunofluorescent IgM antibodies after treatment. ${ }^{5}$

These two patients show that $C$ trachomatis may cause severe chronic peritoneal infections with chronic ascites formation. Timel diagnosis and correct treatment lead to rapid cure.

We thank Dr L Matter, of the Institute of Microbiology, St Gallen, for the serological work up, Dr M Zimmerli for advice, and Mrs C Frei for thed manuscript.

\section{References} 1 Oriel JD. Epidemiology of genital chlamydia infections. Infection 1982;10(suppl):532-9. Chlamydia trachomatis as possible cause of peritonitis and perihepatitis in young women Br Med F 1978;i:1022-4.

3 Shabot JM, Roark GD, Truant AL. Chlamydia trachomatis in the ascitic fluid of patients wit hronic liver disease. Am f Gastroenterol 1983;78:291-4.

4 Onsrud $M$. Perihepatitis in pelvic inflammatory disease-association with intrauterine contracepes tion. Acta Obstet Gynecol Scand 1980;59:69-71

5 Treharne JD. Chlamydia trachomatis: serological diagnosis. Infection 1982;10(suppl 1):525-31. (Accepted 30 April 1986)

\title{
Cigarette smoking and risk of premature stroke in men and women
}

\author{
RUTH BONITA, ROBERT SCRAGG, ALISTAIR STEWART, RODNEY JACKSON, \\ ROBERT BEAGLEHOLE
}

\begin{abstract}
A case-control study was carried out of the relation between cigarette smoking and hypertension and stroke. A total of 132 cases of stroke ( 79 in men, 53 in women) identified as a part of a population based register were compared with 1586 controls (1017 men, 569 women) from a survey of cardiovascular risk factors conducted in the same population. Cigarette smokers had a threefold increase in the risk of stroke compared with current non-smokers. This association remained significant after adjusting for hypertension. Those who both smoked and had hypertension had an increased risk of stroke of almost 20 -fold compared with those who neither smoked nor had hypertension.

Overall, in this population roughly $37 \%$ of stroke events may be attributed to cigarette smoking and $36 \%$ to hypertension.
\end{abstract}

\section{Introduction}

High blood pressure is consistently reported as the most important known risk factor for stroke. ${ }^{1-4}$ Other risk factors such as cigarette smoking or serum lipid, blood glucose, and plasma fibrinogen concentrations have shown varying associations. ${ }^{34}$ In particular,

Department of Medicine, School of Medicine, University of Auckland, Auckland, New Zealand

RUTH BONITA, MPH, PHD, research officer

Department of Community Health and General Practice, School of Medicine,

University of Auckland, Auckland, New Zealand

ROBERT SCRAGG, MB, PHD, senior lecturer in epidemiology

ALISTAIR STEWART, BSC, DIPSC, biostatistician

RODNEY JACKSON, мB, DCOMH, National Heart Foundation of New

Zealand training fellow in epidemiology

ROBERT BEAGLEHOLE, MD, FRACP, associate professor of epidemiology

Correspondence to: Dr Bonita. many studies have failed to identify cigarette smoking as significant risk factor for stroke. When a positive association has been found this has usually been confined to young men..$^{56}$

We present a population based case-control analysis of the association of cigarette smoking and hypertension with strok in both men and women. The proportions of stroke events thaf could be attributed to smoking and hypertension are also estimate $\bar{\Phi}$ as this does not appear to have been done before. In addition, the study investigates the possible synergism between smoking an hypertension.

\section{Subjects and methods}

Cases of stroke were identified from a population based cardiovascula disease register, in which a 50\% random sample of all new episodes of strokeె in Auckland was studied in the year ending 1 March 1982. The study ared (population 829545) encompassed one quarter of the total population of New Zealand. Full details of the case finding methods have been published.o The diagnostic criteria and methods were based on the World Healtb Organisation guidelines. ${ }^{8}$ Stroke was defined as the rapid onset of focat. neurological deficit, presumably of vascular origin, lasting 24 hours oN longer or leading to death. Patients with subarachnoid haemorrhage wer:్ excluded.

Information was obtained from patients using a standard questionnaire a? soon after the event as possible. If the patient had died the samo questionnaire was administered to a close relative after six weeks. Detailक about treatment for high blood pressure and cigarette smoking werẹ collected. Current pharmacological treatment for high blood pressure waso used as a surrogate measure of hypertension. A current smoker was define $\Phi$ as a person smoking at least one cigarette a day.

Controls for the analysis came from a population based survey if

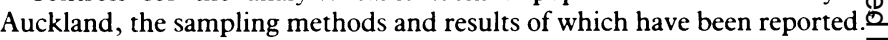
Briefly, 1017 men and 569 women aged 35-64 were interviewed betweer January and July 1982 after being randomly selected from the $198 \mathrm{~b}$ Auckland general electoral rolls (response rate $82 \%$ ). The questionnairo included the same questions about blood pressure history and cigarette smoking as were asked of the patients with stroke.

Analyses were restricted to events that occurred in men and women aged 
BRITISH MEDICAL JOURNAL VOLUME $293 \quad 5$ JULY 1986

35-64. Odds ratios (OR), used as estimates of relative risks, were calculated using the Mantel-Haenszel method, controlling for age. ${ }^{10} \mathrm{Con}$ fidence limits $(C L)$ of the relative risks were calculated by the test based method of Miettinen.$^{10}$ As a measure of the importance of smoking and hypertension to public health population attributable risks were calculated using the maximum likelihood method of Whittemore. "Multiplicative and additive models were compared using the method of Breslow and Storer. ${ }^{12}$

\section{Results}

Table I gives the age and sex distribution of the patients with stroke (cases) and the community controls. A total of 132 cases ( 79 men, 53 women) were available for comparison with 1586 controls (1017 men, 569 women). The cases included 105 patients with a first episode of stroke and 27 with recurrent strokes. Results are presented for the total group since these were the same whether or not analyses were restricted to the incident cases.

TABLE $\longmapsto$ Patients with stroke and community controls distributed by age, sex, hypertension, and smoking state

\begin{tabular}{|c|c|c|c|c|}
\hline & \multicolumn{2}{|c|}{ Patients with stroke } & \multicolumn{2}{|c|}{ Community controls } \\
\hline & Men & Women & Men & Women \\
\hline \multirow{2}{*}{\multicolumn{5}{|c|}{$\begin{array}{l}\text { Total } \\
\text { Age (years): }\end{array}$}} \\
\hline & & & & \\
\hline $35-44$ & 10 & 3 & 226 & 201 \\
\hline $45-54$ & 21 & 16 & 430 & 194 \\
\hline $55-64$ & 48 & 34 & 361 & 174 \\
\hline Hypertensive & 35 & 22 & 111 & 74 \\
\hline Smoker & 43 & 23 & 284 & 140 \\
\hline Both hypertensive and smoker & 16 & 8 & 22 & 11 \\
\hline
\end{tabular}

\section{HYPERTENSION}

Those being treated for hypertension at the time of the stroke were compared with those not currently having treatment. This second group included subjects who had been treated for hypertension in the past. Altogether 111 men $(11 \%)$ and 74 women $(13 \%)$ in the control group were receiving treatment for hypertension compared with $35(44 \%)$ of the men and $22(42 \%)$ of the women with stroke. Table II shows the relation between hypertension and the risk of stroke, controlling for age. For men and women combined hypertension was associated with a fourfold increase in the risk of stroke (OR $4 \cdot 1 ; 95 \% \mathrm{CL} 2 \cdot 8,5 \cdot 7)$. The association was stronger in men than in women but not significantly so $(\mathrm{p}>0.05)$.

TABLE II-Risk of stroke associated with hypertension and smoking, controlling for age. Results expressed as odds ratios

\begin{tabular}{lccc}
\hline Risk factor & Men & Women & Both sexes* \\
\hline Hypertension & $5 \cdot 0(3 \cdot 2,7 \cdot 8) \dagger$ & $3 \cdot 0(1 \cdot 7,5 \cdot 3)$ & $4 \cdot 1(2 \cdot 8,5 \cdot 7)$ \\
Smoking & $3 \cdot 1(2 \cdot 0,4 \cdot 9)$ & $2 \cdot 6(1 \cdot 4,4 \cdot 6)$ & $2 \cdot 9(2 \cdot 0,4 \cdot 1)$ \\
\hline
\end{tabular}

^Also controlling for sex

†95\% Confidence limits in parentheses; all categories significant $(p<0.001)$.

\section{CIGARETTE SMOKING}

Current cigarette smokers were compared with subjects not smoking at the time of the stroke. This second group included ex-smokers. Among the controls $284(28 \%)$ of the men and $140(25 \%)$ of the women were current smokers compared with $43(54 \%)$ and $23(43 \%)$ of the men and women with stroke. Smoking was significantly associated with an increased risk of stroke (OR 2.9; 95\% CL 2.0, 4.1) (table II). As with hypertension the relation between cigarette smoking and stroke was significant in both men and women; the difference in risk between the sexes, however, was not significant.

Figure 1 shows evidence of a dose response relation between the number of cigarettes smoked and the risk of stroke. The risk for those smoking 1-20 cigarettes a day was 3.3 compared with non-smokers (95\% CL $2 \cdot 0,5 \cdot 5$ ), while the risk for heavier smokers (more than 20 cigarettes a day) was $5 \cdot 6$ $(95 \%$ CL $3 \cdot 2,9 \cdot 9)$ compared with non-smokers. The pattern was similar when men and women were analysed separately. No significant difference in

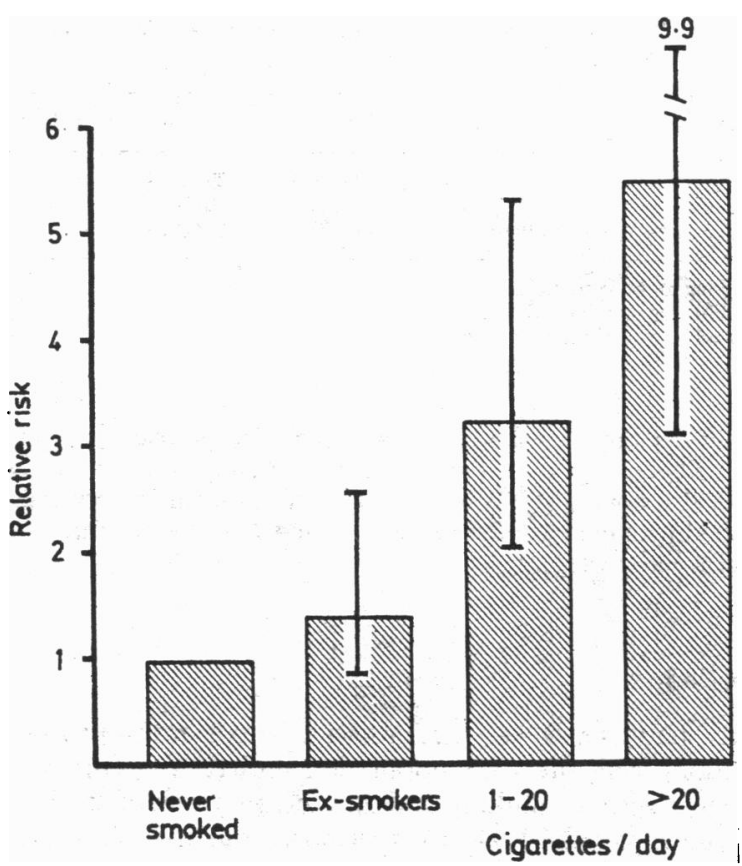

FIG 1-Cigarette smoking and risk of stroke, adjusted for age and sex Bars are $95 \%$ confidence limits.

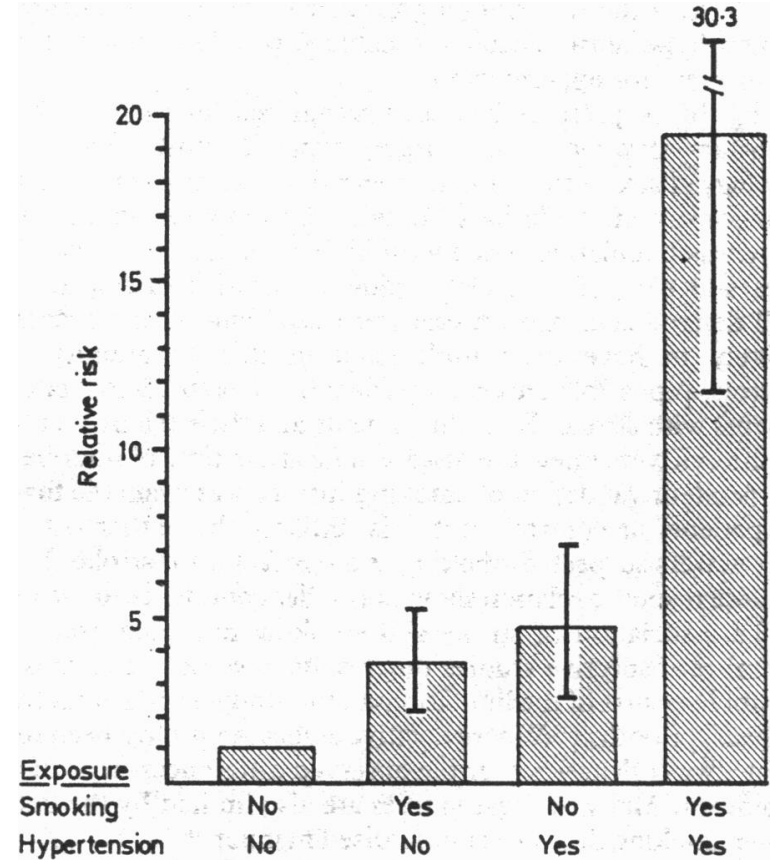

FIG 2-Smoking, hypurtension, and risk of strokc, adjusted for age and sex. Bars are $95 \%$ confidence limits.

risk was found between ex-smokers and non-smokers (OR 1·4; $95 \%$ CL $0 \cdot 8$, 2.6).

Calculations by the Mantel-Haenszel method showed that cigarette smoking and hypertension did not confound each other's association with an increased risk of stroke. By contrast, figure 2 shows that the risk associated with both variables combined $(\mathrm{OR} 18 \cdot 6 ; 95 \% \mathrm{CL} 11 \cdot 6,30 \cdot 3)$ was similar to the product of the risk of smoking (OR $3.4 ; 95 \% \mathrm{CL} 2 \cdot 1,5 \cdot 3)$ and hypertension (OR $4 \cdot 4 ; 95 \%$ CL $2 \cdot 7,7 \cdot 1$ ). The use of Breslow and Storer's methods confirmed that the relation was multiplicative rather than additive, suggesting a synergistic effect between smoking and hypertension on the risk of stroke.

Estimates were made of the proportion of stroke events that could be attributed to smoking or hypertension, or both. Table III shows that in this population cigarette smoking and hypertension were equally important in both men and women. Overall, $37 \%$ and $36 \%$ of the stroke events could be attributed to cigarette smoking and hypertension, respectively. Roughly two 
TABLE III-Percentage of cases of stroke attributable to smoking or hypertension or both, controlling for age

\begin{tabular}{|c|c|c|c|}
\hline Risk factor & Men & Women & Both sexes \\
\hline Smoking & $40(25,54) \ddagger$ & $29(12,46)$ & $37(26,48)$ \\
\hline Hypertension $\dagger$ & $37(24,49)$ & $30(14,46)$ & $36(26,46)$ \\
\hline Smoking or hypertension or both & $64(49,79)$ & $50(29,71)$ & $58(46,70)$ \\
\hline
\end{tabular}

*Controlling for hypertension.

tControlling for smoking.

$\$ 95 \%$ Confidence limits in parentheses.

thirds of the stroke events in men and half of the stroke events in women were attributable to these two risk factors. Sixteen of the men $(20 \%)$ and eight of the women $(15 \%)$ with stroke were exposed to both risk factors compared with only 22 of the men $(2 \%)$ and 11 of the women $(2 \%)$ in the control group (table I).

\section{Discussion}

This analysis based on patients with stroke and controls sampled at random from the same population showed a strong association between cigarette smoking and an increased risk of stroke in men and women aged 35-64. Furthermore, the risk associated with cigarette smoking was similar to that associated with hypertension in men and women. A dose response relation was found between the number of cigarettes smoked and the risk of stroke. The relative risks presented are likely to be conservative because for both cases and controls the non-smoking category included ex-smokers and the non-hypertension category included people with a past history of treatment for hypertension.

High blood pressure has been recognised for years as the most important risk factor for stroke, while in most reviews of the aetiology of stroke the evidence regarding cigarette smoking has not been consistent. ${ }^{3-4}$ We have confidence in our results because the study was population based with high response rates (over $95 \%$ of cases and $82 \%$ of controls), reducing the risk of selection bias. Well defined standard criteria were used and stroke events were unlikely to have been undetected in this community among controls. A possible uncertainty concerns the risk factor state of the patients with stroke. Both the patients and their relatives as well as the interviewers knew the disease state at the time of interview. No independent validation of smoking history was available for either the patients or controls, but it is unlikely that either patients or interviewers suspected smoking as a risk factor for stroke. Further, the dose response relation shown provides confidence in the results.

The association of stroke and smoking has been examined in several retrospective studies but results have not been consistent, possibly because of the limitations of the study design or methods of analysis, or both. ${ }^{13-17}$ Where positive associations have been found it is not always clear whether the observed differences are statistically significant. Many of these studies are also limited by the failure to gather smoking data in a standardised manner. ${ }^{13-17}$

Prospective studies of the relation between smoking and mortality from stroke, usually confined to men, ${ }^{18-26}$ have also yielded conflicting results. While some studies have shown an overall association between smoking and subsequent stroke ${ }^{18-22}$ and others have shown this in restricted age groups, ${ }^{23}$ a similar number have failed to detect a positive association. ${ }^{2428}$ An unequivocal association has not been found in women. ${ }^{529}{ }^{30}$ No explanation is apparent for these discordant results, though the lack of significant findings may possibly be due to the small numbers of patients in several of these studies.

Estimates of the proportions of cases of stroke in the community attributable to high blood pressure (36\%) and cigarette smoking $(37 \%)$ in this study suggest that these risk factors are of comparable importance for public health. Evidence of a synergistic effect of smoking and hypertension on the risk of stroke had been suggested in a study of Harvard alumni, although in that study the presence of synergism was not evaluated statistically and the risk factor data were not collected in a standardised manner. ${ }^{31}$

Though our study was confined to subjects aged less than 65 , a quarter of all strokes occur in this age group. ${ }^{32}$ Extrapolation from our results to the population of New Zealand aged 35-64 suggests that roughly $600(95 \%$ CL 470,740$)$ new episodes of stroke each year may be explained by smoking or hypertension, or both, among people in this age group.

Given the large decline in mortality from stroke in New Zealan $\$$ in recent years, ${ }^{33}$ relatively little of which can be explained by improvements in the treatment of hypertension, ${ }^{3+}$ the contributio of the decline in cigarette smoking which has also occurred over thi period $^{35}$ warrants further attention. Further reduction in thi prevalence of smoking in the population, especially in those already being treated for hypertension, may contribute more to the prevention of stroke than has previously been acknowledged.

This research was supported by the Medical Research Council of New Zealand and the National Heart Foundation of New Zealand. We thank the

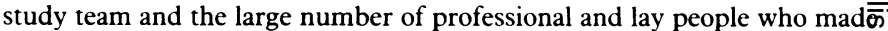
the study possible. Critical comments on an earlier draft by Professors $P$ क Scott, J D K North, and S R Leeder are also acknowledged.

\section{References}

1 Kannel WB, Wolf PA, Verter J, McNamarra PN. Epidemiologic assessment of the role of bloos pressure in stroke: the Framingham study. FAMA 1970;214:301-10.

2 Kannel WB. Hypertension, blood lipids, and cigarette smoking as co-risk factors for coronar. heart disease. Ann NY Acad Sci 1978;304:128-39.

3 Ostfeld AM. A review of stroke epidemiology. Epidemiol Rev 1980;2:136-51.

Dyken ML, Wolf PA, members of Subcommittee on Risk Factors and Stroke of the Sutch Council. Risk factors in stroke, special report. Stroke 1984:15:1105-11.

5 Salonen JT, Puska P, Tuomilehto J. Homan K. Relation of bond pressure, serum lipds, smoking to the risk of cerebral stroke: a longitudinal study in eastern Finland. Strokeg
$1982 ; 13: 327-33$.

6 Wolf PA. Current status of risk factors for stroke. Neurology Clinics 1983;1:317-21.

Bonita R, Beaglehole R, North JDK. The long term monitoring of cardiovascular disease: is it? feasible? Community Health Stud 1983;7:111-6.

Hatano S. Control of stroke in the community. Methodological considerations and protocol of $W H Q$ stroke register. Geneva: WHO, 1973. (Document No CVD/S/73.6, Rev 1.)

9 Jackson R, Beaglehole R, Stewart AW. Blood pressure levels and the treatment of hypertension in Auckland, 1982. NZ Med F 1983;96:751-4.

10 Breslow NE, Day NE. Statistical methods in cancer research. Vol 1. The analysis of case-contr $\$$ studies. Lyon: International Agency for Research on Cancer, 1980. (IARC scientific publication No 32 .

11 Whittemore AS. Estimating attributable risk from case-control studies. Am $\mathcal{J}$ Epidemio

12 Breslow NE, Storer BE. General relative risk functions for case-control studies. Am $\mathcal{J}$ Epidemio
19. 1985;122:149-62.

13 MacKay A, Nias BC. Strokes in young and middle aged: consequences to the family and to society I R Coll Physicians Lond 1979;13:106-12.

14 Fogelholm R, Aho K. Ischaemic cerebrovascular disease in young adults. Acta Neurol Scand 1973;49:415-27.

15 Abu-Zeid HAH, Choi NW, Maini KK, Hsu PH, Nelson NA. Relative role of factors associate with cerebral infarction and cerebral hemorrhage. Stroke 1977;8:106-12.

16 Bell BA, Ambrose J. Smoking and the risk of a stroke. Acta Neurochir 1982;64:1-7.

17 Herman B, Leyton ACM, Van Luijk JH, Franken CWGM, Opdecoul AAW, Schulte BPM. AD evaluation of risk factors for stroke in a Dutch community. Stroke 1982;13:334-9.

18 Hammond EC, Horn D. Smoking and death rates - report on forty-four months of follow-up of 187783 men: total mortality. FAMA 1958;166:1159-72.

19 Paffenbarger RS, Wing AL. Chronic disease in former college students. Early precursors of nonfatal stroke. Am f Epidemiol 1971;94:524-30.

20 Doll R, Peto R. Mortality in relation to smoking: 20 years' observations on male British doctors BrMed f 1964;i:1399-1410.

21 Rogot E, Murray JL. Smoking and causes of death among US veterans: 16 years of observation Public Health Rep 1980;95:213-22.

22 Paffenbarger RS, Williams JL. Chronic disease in former college students. Early precursors of fatal stroke. Am $\mathcal{f}$ Public Health 1967;57:1290-4.

fatal stroke. Am $\mathcal{F}$ Public Health 1967;57:1290-4.
23 Wolf PA, Dawber TR, Thomas HE, Kannel WB. Epidemiologic assessment of chronic atriat Wolf PA, Dawber TR, Thomas HE, Kannel WB. Epidemiologic assessment of chro
fibrillation and risk of stroke: the Framingham study. Neurology $(N Y)$ 1978;28:973-7.

24 Paffenbarger RS, Brand RJ, Sholtz RI, Jung DL. Energy expenditure, cigarette smoking and blood pressure level as related to death from specific diseases. Am $\mathcal{E}$ Epidemiol 1978;108:12-8. O 25 Brett GZ, Benjamin B. Smoking habits of men employed in industry, and mortality. Br Med F $1968 ;$;ii: $82-5$.

26 Okada $\mathrm{H}$, Horibe $\mathrm{H}$, Ohno $\mathrm{Y}$, Hayakawa $\mathrm{N}$, Aoki N. A prospective study of cerebrovascula disease in Japanese rural communities, Akabane and Asahi. Stroke 1976;7:599-607.

27 Nomura A, Comstock GN, Kuller L, Tonascia JA. Cigarette smoking and strokes. Strokg 1974;5:483-6.

28 Ostfeld AM, Shekelle RB, Klawans H, Tufo HM. Epidemiology of stroke in an elderly welfare

population. Am $\mathcal{f}$ Public Health 1974;64:450-8.
29 Doll R, Gray R, Hafner B, Peto R. Mortality in relation to smoking: 22 years' observations i female British doctors. Br Med f 1980;280:967-7

30 Pettiti DB, Wingerd J, Pellegrin F, Ramcharan S. Risk of vascular disease in women: smoking,

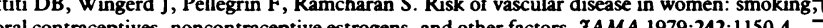
oral contraceptives, noncontraceptive estrogens, and other factors. JAMA 1979;242:1150-4. Paffenbarger RS, Wing AL. Chronic disease in former college students: early precursors of non
fatal stroke. Am $\mathcal{F}$ Epidemiol 1971;94:524-30.

Beaglehole $R$, Netratity rates of cerebrovasculan disease in Auckland, New Zealand. Am $\mathcal{F}$ Epidemiol 1984;120:236-43.

33 Bonita $R$, Beaglehole $R$. Trends in cerebrovascular disease mortality in New Zealand. NZ Med

$1982 ; 95: 411-4$.
34 Bonita R, Beaglehole R. Does the treatment of hypertension explain the decline in strok mortality? BrMed J 1986;292:191-2.

35 Hay DR, Foster FH. Intercensal trends in cigarette smoking in New Zealand. 1: Age, sex and ethnic status. NZ Med f 1984;97:283-5.

(Accepted 17 April 1986) 